\title{
Non-conventional haemorrhoid symptoms reported by female patients
}

\author{
(D) JAMES KENT ${ }^{1}$, (1) JACQUES OOSTHUIZEN², (1) CELIA WILKINSON³ \\ ${ }^{1}$ Bentley Health Service and St John of God Healthcare, Perth, Western Australia \\ 2Edith Cowan University, Perth, Western Australia \\ ${ }^{3}$ Curtin University, Perth, Western Australia
}

\begin{abstract}
Objective: This study was undertaken to assess the importance of several non-conventional symptoms, including perianal hygiene, to female patients undergoing haemorrhoidectomy and to correlate these with the presence of associated skin tags. Materials and Methods: A single surgeon retrospective study used a customised questionnaire aimed specifically at female patients undergoing Milligan-Morgan haemorrhoidectomy with excision of significant associated skin tags to assess non-conventional symptoms. Postal surveys were sent to 71 women with 52 replies, three exclusions due to hybrid procedures and 49 patients analysed.

Results: Painful prolapse and bleeding were still the most common reasons for undergoing haemorrhoidectomy but perianal hygiene (the ability to keep the area clean after toileting and during the day) was significant in nearly $60 \%$ of patients. Itching (40\%), concerns about odour (35\%), general discomfort (35\%) and embarrassment in case their partner saw the haemorrhoids or skin tags was significant in $27 \%$.

Conclusion: Haemorrhoidectomy with complete removal of the skin tags resulted in statistically significant improvement in the parameters of odour, pruritis, toileting and less interference with the patients sex life. Surprisingly some aspects of continence were improved. The study shows that non-conventional symptoms are important in female patients and may influence the patients perception of the success of the operation. A simple modification of Golighers' classification is proposed to reflect the presence of skin tags and to guide assessment of the success of novel treatments for haemorrhoids in women.
\end{abstract}

Keywords: Haemorrhoids; treatment; hygiene

\section{INTRODUCTION}

Even when there is still debate concerning precise aetiopathogenesis, the symptoms attributed to haemorrhoids tend to correlate with their established classification. Consensus agreement on haemorrhoidal grade is important in deciding about treatment options and in a comparison of management outcomes. In coloproctological practice, there is universal use of the Goligher grades with a traditional separation of internal and external haemorrhoids dependent upon origin above or below the dentate line and where there is either a mucosal or epidermal covering, respectively. ${ }^{1,2}$ There is, however, a frequent disparity between the physical symptoms of haemorrhoids and their signs with a bias towards specific surgical managements based more upon their anatomical configuration than upon patientreported symptoms. ${ }^{3}$ All proctologists have seen patients with symptomatic haemorrhoids which do not bleed but where there are significant and persistent complaints such as anal discomfort,

Address for Correspondence: Mr James Kent, Consultant Surgeon, 2/19 Mills Street, Cannington, Western Australia, 6107 Phone: +61 0893561544 E-mail: parousiamedical @bigpond.com ORCID ID: orcid.org/0000-0003-0115-0759 Received: 23 August 2019 Accepted: 12 May 2020

${ }^{\circledR}$ Copyright 2020 by the International Society for Pelviperineology / Pelviperineology published by Galenos Publishing House. 
soiling, leakage and difficulty with perianal hygiene, each of which are not addressed in the standard haemorrhoidal classification system. The acceptance and use of a symptom-led classification would be aimed more at specific symptom improvement rather than at a restoration of normal anatomy. Moreover, these isolated particular symptoms can direct management, influencing clinical outcomes and surgical satisfaction. This short communication reports the use of a customized questionnaire specifically aimed at female patients undergoing Milligan-Morgan haemorrhoidectomy, asking them about a range of non-standard haemorrhoidal symptoms and correlating their outcome with the surgical elimination of anal skin tags.

\section{PATIENTS AND METHODS}

The conduct of this retrospective analytical study was approved by the Edith Cowan University Research Ethics Committee (project number: 17024, date: 19 January 2017). Consecutive female patients under the care of one surgeon coming to MilliganMorgan haemorrhoidectomy for symptomatic haemorrhoids with significant skin tags were included for analysis between June 2013 and December 2017. Patient demographic details (age, marital status and country of birth) were recorded along with the broad indications for surgery and the specific patient-related symptomatic concerns leading to haemorrhoidectomy. Patients returned a pre- and postoperative questionnaire including their principal reasons for undergoing haemorrhoidectomy and broad questions inquiring about the presence of a wet bottom, the use of panty liners, toileting, concerns about odour, perianal irritation and disturbance of sexual function (pain, embarrassment). Symptoms were graded for frequency using a Likert scale of 1-4 where $1=$ none, $2=>$ once per month but $<$ once per week; $3=>$ once per week but $<$ daily and $4=$ daily. Surgical assessment at 3 postoperative months determined the presence of any mucoanal prolapse during straining and the presence or absence of skin tags. No patient had significant residual skin tags. For the purposes of the study a skin tag was defined as any redundant skin-covered extension of tissue at the anal verge which was of sufficient size that it could be grasped between the forefinger and the thumb and which would be the soft-tissue traditionally grasped with forceps at the commencement of a Milligan-Morgan haemorrhoidectomy. ${ }^{4}$ Inquiry about continence status was assessed simply (yes/ no) and if present was graded for leakage of solid/ liquid stool or for gas with frequency reported on a Likert scale. In the interests of brevity, and to encourage reply in a survey format, formal continence scoring was not performed. All patients completed the survey at least 12 months after the procedure.

\section{Statistical Analysis}

Analysis of data was performed with SPSS Version 25.0 software (Chicago, IL). Categorical data were assessed by a chi-square test where indicated. Comparative data was assessed before and after surgery with the non-parametric Mann-Whitney $U$ or McNemars test depending upon data distribution. P values $<0.05$ wereconsidered as significant.

\section{RESULTS}

Postal surveys were sent to 71 women with 52 replies $(73.2 \%$ response). Three patients were excluded due to hybrid procedures. The mean age was 55 years (range: 28-77). Table 1a shows how patients rated their symptoms leading into surgery with Table $1 \mathrm{~b}$ showing the principal single reason for operation. Threequarters of patients nominated bleeding as very or extremely important in their decision with over half listing painful prolapse or irritation wearing underwear. One-third had major concerns about odour, 40\% perianal itching and one-quarter expressed significant concerns about how the appearance of the anus was perceived by their partner. As the single most important reason for surgery half the patients nominated bleeding with $20.4 \%$ decisively concerned about perianal hygiene and $12.2 \%$ about the appearance of the anus. After an explanation distinguishing haemorrhoidal prolapse from skin tags by asking whether the tissue palpable after defaecation could be reduced or felt like skin that could not be reduced, $44.2 \%$ of patients attributed their symptoms to prolapse with $50 \%$ to tags and $5.8 \%$ unsure. See Tables $1 \mathrm{a}$ and $\mathrm{b}$.

Table 2 shows haemorrhoid-related symptoms before and after surgery in those cases (49 patients) where surgical examination showed an absence of postoperative skin tags (as defined).

\section{Table 1a. Patient rating of importance in the indication for} haemorrhoidectomy

\begin{tabular}{|l|l|}
\hline Symptom & $\begin{array}{l}\text { Rated very } \\
\text { or extremely } \\
\text { important by the } \\
\text { patient (\%) }\end{array}$ \\
\hline Bleeding & 75.5 \\
\hline Painful prolapse & 57.1 \\
\hline Perianal hygiene & 59.1 \\
\hline Irritation from underwear (g string etc.) & 16.3 \\
\hline Embarrassment if partner sees & 26.6 \\
\hline Concerns about odour & 34.6 \\
\hline General discomfort & 34.6 \\
\hline Itching & 40.4 \\
\hline $\begin{array}{l}\text { 78\% of patients reported multiple symptoms as being important or very } \\
\text { important }\end{array}$ \\
\hline
\end{tabular}




\begin{tabular}{|c|c|}
\hline Indication & Percentage \\
\hline Bleeding & 57.1 \\
\hline Perianal hygiene & 20.4 \\
\hline Appearance & 12.2 \\
\hline Other & 8.2 \\
\hline Null (patients did not complete the question) & 2.1 \\
\hline
\end{tabular}

\begin{tabular}{|c|c|c|c|c|}
\hline & & Before & After & $p$ value \\
\hline Symptom & Frequency & $\mathrm{n} / \%$ & $\mathrm{n} / \%$ & \\
\hline \multirow{5}{*}{$\begin{array}{l}\text { Wet } \\
\text { bottom }\end{array}$} & Never & $26(53.1)$ & $37(75.5)$ & \multirow{5}{*}{0.075} \\
\hline & Once per month & 8 (16.3) & $4(8.2)$ & \\
\hline & Once per week & $6(12.2)$ & $5(10.2)$ & \\
\hline & Every day & $8(16.3)$ & $3(6.1)$ & \\
\hline & Null & $1(2.0)$ & - & \\
\hline \multirow{5}{*}{$\begin{array}{l}\text { Panty } \\
\text { liners }\end{array}$} & Never & $33(67.3)$ & $41(83.7)$ & \multirow{5}{*}{0.083} \\
\hline & When going out & $5(10.2)$ & $6(1)$ & \\
\hline & $<$ once per week & $1(2)$ & 0 & \\
\hline & Every day & 9 (18.4) & $2(4)$ & \\
\hline & Null & $1(2)$ & - & \\
\hline \multirow{4}{*}{ Odour } & Never & $26(53.1)$ & $37(75.5)$ & \multirow{4}{*}{0.001} \\
\hline & Sometimes & $15(30.6)$ & $9(18.4)$ & \\
\hline & Often & $3(6.1)$ & $1(2.0)$ & \\
\hline & Always & $5(10.2)$ & $2(4.1)$ & \\
\hline \multirow{4}{*}{$\begin{array}{l}\text { Itchy } \\
\text { bottom }\end{array}$} & Never & $13(26.5)$ & $31(63.3)$ & \multirow{4}{*}{0.004} \\
\hline & $\begin{array}{l}<\text { once per } \\
\text { month }\end{array}$ & $16(32.7)$ & $12(24.5)$ & \\
\hline & Every week & $14(28.6)$ & $6(12.2)$ & \\
\hline & Every day & $6(12.2)$ & 0 & \\
\hline \multirow{5}{*}{$\begin{array}{l}\text { Interfere } \\
\text { with sex } \\
\text { life }\end{array}$} & Never & $20(40.8)$ & $37(75.5)$ & \multirow{5}{*}{$<0.0001$} \\
\hline & Sometimes & $18(36.7)$ & $9(18.4)$ & \\
\hline & Often & $3(6.1)$ & $1(2.0)$ & \\
\hline & Always & $6(12.2)$ & 0 & \\
\hline & Null & $2(4.1)$ & $2(4.1)$ & \\
\hline \multirow{3}{*}{$\begin{array}{l}\text { After } \\
\text { stooling }\end{array}$} & $\begin{array}{l}\text { Use a lot of toilet } \\
\text { paper }\end{array}$ & $34(69.4)$ & $15(30.6)$ & $<0.0001$ \\
\hline & Use baby wipes & $28(57.1)$ & $15(30.6)$ & 0.001 \\
\hline & Shower & $21(42.9)$ & $10(20.4)$ & 0.003 \\
\hline \multicolumn{2}{|c|}{ Afraid to use toilet when out } & $21(42.9)$ & $9(18.4)$ & 0.006 \\
\hline \multicolumn{5}{|l|}{$\mathrm{n}$ : Number } \\
\hline
\end{tabular}

All parameters improved following haemorrhoidectomy with significant reductions in the incidence and frequency of patient perceived odour, perianal itch and disturbance of sexual dysfunction (as broadly defined). Patients also perceived that the basic quality of their toileting was improved after surgery with less use of toilet paper or fear of using unfamiliar toilets. Patients also noted less likelihood of a wet anus or the requirement for panty liners although these parameters of assessment did not reach statistical significance. See Table 2. In broad terms when asked preoperatively about an overall continence history, nine patients (18.4\%) admitted to an occasional inability to control their bowels. Table 3 shows the continence status of the patient cohort before and after surgery. On specific questioning regarding any type of loss (solid, liquid or gaseous) prior to surgery 47 (95.9\%) respondents were completely continent for solids with two cases reporting occasional solid stool leakage (one $<$ once per week and one $<$ once per month). There were seven patients with leakage of liquid stool (four $<$ once per month, two < once per day and one daily) and eight reporting gaseous loss (one $<$ once monthly, one $<$ once weekly, three $<$ daily but $>$ once per week and three daily). Following surgery there was continence for solid stool, liquid stool and gas in 48 (98\%), 47 (96\%) and 46 (94\%) patients, respectively. One patient reported $<$ weekly solid stool loss, with two cases reporting liquid stool loss (one $<$ weekly and one $>$ weekly but $<$ daily) and three reporting gaseous loss (one $<$ weekly, one $<$ daily but $>$ weekly and one daily; $p=0.027$ ). See Table 3 .

\section{DISCUSSION}

This small, single-surgeon, retrospective study shows that Milligan-Morgan haemorrhoidectomy with excision of skin tags in female patients results in a significant reduction in nonconventional haemorrhoidal symptoms not usually included in haemorrhoidal classifications, most notably concerns about odour, the appearance of the anal area, perianal hygiene and sexual function. Given the increasingly wide range of surgical options for haemorrhoid management, there still remains no standardization concerning the clinical findings following surgery and no validated scoring system yet available for recurrence with most as in our study reliant upon a combination of clinical signs and patient-reported symptoms. ${ }^{5}$ In circumstances, however, where non-conventional symptoms are a trigger for surgery, the rigid requirement for registration of patients as recurrence-free when there are no symptoms at all, ${ }^{6}$ may not in some cases be appropriate as a measure of surgical success. It is the author's impression that many women coming to surgery for haemorrhoids have symptoms related to skin tags, a feature not represented within the Goligher classification. It 


\begin{tabular}{|c|c|c|c|}
\hline Continence status & Before (\%) & After (\%) & $p$ value \\
\hline \multicolumn{3}{|l|}{ Solid stool loss } & \multirow{6}{*}{0.317} \\
\hline Complete continence & $47(95.9 \%)$ & $48(98.0 \%)$ & \\
\hline Daily loss & - & - & \\
\hline$<$ daily but $<$ once weekly & - & $1(2.0 \%)$ & \\
\hline $\begin{array}{l}<\text { once per week but }>\text { once } \\
\text { monthly }\end{array}$ & $1(2.0 \%)$ & - & \\
\hline$<$ once per month & $1(2.0 \%)$ & - & \\
\hline \multicolumn{3}{|l|}{ Liquid stool loss } & \multirow{6}{*}{0.020} \\
\hline Complete continence & $42(86 \%)$ & $47(96.0 \%)$ & \\
\hline Daily loss & $1(2.0 \%)$ & - & \\
\hline$<$ daily but $<$ once weekly & $2(4.0 \%)$ & $1(2.0 \%)$ & \\
\hline $\begin{array}{l}<\text { once per week but }>\text { once } \\
\text { monthly }\end{array}$ & - & $1(2.0 \%)$ & \\
\hline$<$ once per month & $4(8.0 \%)$ & - & \\
\hline \multicolumn{3}{|l|}{ Gaseous loss } & \multirow{6}{*}{0.027} \\
\hline Complete continence & $41(84.0 \%)$ & $46(94.0 \%)$ & \\
\hline Daily loss & $3(6.0 \%)$ & $1(2.0 \%)$ & \\
\hline$<$ daily but $<$ once weekly & $3(6.0 \%)$ & $1(2.0 \%)$ & \\
\hline $\begin{array}{l}<\text { once per week but }>\text { once } \\
\text { monthly }\end{array}$ & $1(2.0 \%)$ & $1(2.0 \%)$ & \\
\hline$<$ once per month & $1(2.0 \%)$ & - & \\
\hline
\end{tabular}

is proposed that haemorrhoidal skin tags are a prolongation of the perianal skin which has at its apex an internal haemorrhoid and which with prolapse, has a sliding anodermal component resulting in displacement of the dentate line, protrusion of the redundant anal canal at the anal verge and traction on the external skin. These types of skin tags are to be distinguished from those which are the end- or by-product of a painful perianal haematoma. ${ }^{7}$ It is accepted that there is no uniform definition of a skin tag although for practical purposes it could include tissue $>1.5 \mathrm{~cm}$ in length that can readily be grasped between the thumb and the forefinger and which can be locally excised with preservation of the subdermal fascia. The finding that these patients underwent haemorrhoidectomy largely for bleeding and prolapse is expected, but over one-quarter expressed concerns about their partner's reaction to the anal appearance with one-third perceiving their haemorrhoids as a source of odour and a large proportion troubled by the impact their haemorrhoids had on personal perianal hygiene. Success following haemorrhoidal surgery, (however that is performed), is most frequently judged upon an improvement in postoperative bleeding and prolapse, findings which have been confirmed in studies comparing Milligan-Morgan haemorrhoidectomy with a range of stapled haemorrhoidopexies and with Doppler-guided dearterialization/mucopexy procedures. ${ }^{8-11}$ of importance is our finding that success in surgical outcome may be gained by significant postoperative improvements in non-conventional haemorrhoid-related symptoms. In this study, postoperative patients without skin tags were chosen for assessment, with the hypothesis that management of skin tags in advanced haemorrhoids influences outcome and patient satisfaction. If further studies validate that the described symptomatology is attributed to the skin tags and not the haemorrhoids per se then there would be merit in modifying the Goligher classification to include the presence of skin tags resulting in the new grades $3 \mathrm{~b}$ and $4 \mathrm{~b}$. This would assist as an outcome measure following surgery as well as defining the necessity for hybrid procedures which included en passant skin tag excision when either stapled haemorrhoidopexy or dearterialization/mucopexy was used as the definitive surgical treatment. This modification has the virtue of simplicity. The description of an "external component" by Gerjy et al. ${ }^{12}$ as none, one or few or circumferential is valid but a skin tag can be associated with grade 3 or grade 4 haemorrhoids and the length of the skin tag also needs to be considered. Currently, the addition of a skin tag excision as part of a stapled haemorrhoidopexy does not appear to significantly impact postoperative pain or convalescence. ${ }^{5,10}$ Continence was only broadly assessed in this study with the unexpected finding in small numbers of patients of an improvement in some cases of postoperative continence status. Our patients did not undergo formal continence scoring although there is the possibility that their surgery resulted in an overall improvement of hermetic anal sealing and a diminution in faecal leakage.

There are several limitations to this study. The study reports only a small number of patients and the retrospective nature of the analysis may have introduced bias and the possibility of an alpha error concerning the impact of haemorrhoidectomy on non-conventional symptoms. This study did not control for the possibility that patients with only haemorrhoids could experience similar symptomatology. The impression was, however, that it was the control of larger skin tags in this patient group that improved those symptoms which were "irritative" in nature (perianal itch, underwear irritation and the excessive use of toilet paper for cleansing) and likely also improved sexual functioning. In summary, female patients coming to haemorrhoidectomy are troubled by important non-bleeding, non-prolapse symptomatology which is infrequently asked about or recorded but which can impact surgical success. It is suggested that some of this non-conventional symptomatology is related to an external skin tag component frequently not addressed 
in advanced haemorrhoidal grades by surgical alternatives to haemorrhoidectomy such as the stapled haemorrhoidopexy and dearterialization/mucopexy procedures. The presence of skin tags could be incorporated into a modified Goligher classification system in order to decide about the merits of selective separate skin tag excision in hybrid procedures and as a useful outcome measure following a Milligan-Morgan style haemorrhoidectomy.

\section{CONCLUSIONS}

Even given the limitations of this retrospective study it is clear that the concept of perianal hygiene is important to female patients and that its control is an important measure of the success of any haemorrhoid treatment.

\section{Acknowledgements}

We thank Ms Kerry Staples for her kind assistance with the statistical analysis and Professor Andrew Zbar for his critical review of the manuscript.

\section{ETHICS}

Ethics Committee Approval: The conduct of this retrospective analytical study was approved by the Edith Cowan University Research Ethics Committee (project number: 17024, date: 19 January 2017).

\section{Informed consent: Retrospective study.}

Peer-reviewed: Externally peer-reviewed.

\section{REFERENCES}

1. Goligher JC. Surgery of the Anus, Rectum and Colon. Bailliere Tindal London 1980 4th Edn: 93-4, 96.

2. American Gastroenterological Association medical position statement: Diagnosis and treatment of hemorrhoids. Gastroenterology 2004; 126: 1461-2.
3. Lunniss PJ, Mann CV. Classification of internal haemorrhoids: a discussion paper. Colorectal Dis 2004; 6: 226-32.

4. Hancock BD. Haemorrhoids. Br Med J 1992; 304: 1042-4.

5. Gerjy R, Nystrom PO, Excision of residual skin tags during stapled anopexy does not increase postoperative pain. Colorectal Dis 2007; 9: 754-7.

6. Ratto C, Donisi L, Parello A, Litta F, Doglietto GB. Evaluation of transanal haemorrhoidal dearterialization as a minimally invasive therapeutic approach to hemorrhoids. Dis Colon Rectum 2010; 53 : 803-11.

7. Oh C. Acute thrombosed external hemorrhoids. Mt Sinai Med J 1989; 56: 30-2

8. NisarPJ,AchesonAG, NealKR,ScholefiledJH.Stapled haemorrhoidopexy compared with conventional haemorrhoidectomy: systematic review of randomized, controlled trials. Dis Colon Rectum 2004; 47: 1837 45.

9. Trenti L, Biondo S, Galvez A, Bravo A, Cabrera J, Kreisler E. Distal Doppler-guided transanal hemorrhoidal dearterialization with mucopexy versus conventional hemorrhoidectomy for Grade III and IV hemorrhoids: postoperative morbidity and long-term outcomes. Tech Coloproctol 2017; 21: 337-44.

10. Lin HC, Lian L. Xie SK, Peng H, Tai JD, Ren DL. The tissue-selecting technique: segmental stapled hemorrhoidopexy. Dis Colon Rectum 2013; 56: 1320-4.

11. Zbar AP, Beer-Gabel M, Chiappa AC, Aslam M. Fecal incontinence after minor anorectal surgery. Dis Colon Rectum 2011; 44: 1610-23.

12. Gerjy R, Lindhoff-Larson A, Nystrom P.O. Grade of prolapse and symptoms of haemorrhoids are poorly correlated: result of a classification algorithm in 270 patients. Colorectal disease. 2007;10:694-700. 